\title{
A importância da psicopedagia no desenvolvimento das competências da BNCC no ensino aprendizagem
}

The importance of psycho-pedagogy in the development of BNCC skills in teaching learning

\author{
Angélica Dias Medeiros Junqueira \\ Escola Municipal Guiomar de Campos Miranda, Brasil \\ angelica_mjunqueira@hotmail.com \\ Relindes Dalva De Assis \\ Universidade Federal de Mato Grosso (UFMT)-Brasil \\ relindesdalva@hotmail.com
}

Fecha recepción: 01-03-2020

Páginas 9-18

Fecha aceptación: 20-05-2020

\section{Resumo.}

0 presente artigo, resultado de uma pesquisa bibliográfica metodologicamente estruturada, por meio de fontes teóricas que embasam a busca de respostas sobre 0 tema abordado. Tendo como objetivo analisar a Importância da psicopedagogia no desenvolvimento das competências da BNCC no ensino aprendizagem. Trabalhou-se com os conceitos de psicopedagogia, competências, BNCC e ensino aprendizagem, tomando por base contextualiza-las, pois estão relacionadas, em um contexto social educacional e político bem demarcados e se justifica pela compressão detalhada das competências presente na BNCC e a importância da psicopedagogia na aplicabilidade dessas competências no processo ensino aprendizagem; pois a psicopedagogia age como mediador entre o sujeito e a aprendizagem, investigando, diagnosticando e intervindo mediante as dificuldades de aprendizagem, juntamente com todos envolvidos no processo, buscando assim desenvolver e alcançar todas as competências presentes na BNCC.

Palabras chave: psicopedagogia, competências, bncc, ensino aprendizagem

\begin{abstract}
.
This article, the result of a methodologically structured bibliographic search, using theoretical sources that support the search for answers on the topic addressed. Aiming to analyze the importance of psych pedagogy in the development of BNCC skills in teaching and learning. The concepts of psych pedagogy, skills, BNCC and teaching learning were worked on, based on contextualizing them, as they are related, in a well-demarcated social and political social context and justified by the detailed compression of the skills present in the BNCC and the importance psych pedagogy in the applicability of these competences in the teaching-learning process; because psych pedagogy acts as a mediator between the subject and learning,
\end{abstract}


investigating, diagnosing and intervening through learning difficulties, together with everyone involved in the process, thus seeking to develop and achieve all the skills present in the BNCC.

Keywords: psych pedagogy, skills, bncc, teaching and learning

\section{1.-Introdução.}

As reformas educacionais propostas e colocadas em prática no Brasil é caracterizada por enfatizar o processo ensino aprendizagem, recorrendo a novos recursos pedagógicos ou da tecnologia educacional e por condicionar os objetivos da educação às necessidades da produção e do desenvolvimento econômico do país, as pesquisas se voltam para o professor, para o seu pensamento, sua experiência, para sua vida e seus projetos, suas atitudes e ideais, com o objetivo de incentivar a participação do professor na efetivação das políticas educacionais e na construção do coletivo nas escolas. Diante disso é importante redirecionar o olhar dos profissionais da educação para as necessidades emergentes, aprofundando os conhecimentos e mecanismos que tragam subsídios para a pedagogia da aprendizagem significativa, sendo o fazer pedagógico algo bastante complexo. Os profissionais da Educação encontram muitas dificuldades para lidar com os inúmeros problemas sócio cognitivos que surgem, em especial, os relacionados ao ensino aprendizagem e para solucionar ou minimizar essas situações, os professores devem atuar de forma reflexiva, sempre repensando a sua prática, conscientes de suas limitações e de seu poder transformador. Além disso, faz-se necessário a participação ativa da família, da escola, do aluno e de outros profissionais da Educação e de áreas afins.

Tendo agora a Base Nacional Comum Curricular (BNCC) como um documento de caráter normativo que define o conjunto orgânico e progressivo de aprendizagens essenciais que todos os alunos devem desenvolver ao longo das etapas e modalidades da Educação Básica. (BRASIL, 2016, p. 7) 0 presente artigo, resultado de uma pesquisa bibliográfica metodologicamente estruturada, por meio de fontes teóricas que embasam a busca de respostas sobre o tema abordado, que segundo Gil (2002), é desenvolvido com base em material já elaborado, constituído especificamente de livros e artigos científicos.Tendo como objetivo analisar a Importância da psicopedagogia no desenvolvimento das competências da BNCC no ensino aprendizagem.

Fundamentado nas possibilidades da Base Nacional Comum Curricular (BNCC), para o processo ensino aprendizagem que apresenta suas competências funcionais de maneira crescente para o aperfeiçoamento, com caráter de continuidade no processo educativo, e normatividade definindo o conjunto orgânico e progressivo de aprendizagens essenciais que todos os alunos devem desenvolver ao longo das etapas e modalidades da Educação Básica Brasileira. As competências essenciais presente na BNCC serão trabalhadas nas escolas públicas e particulares brasileiras de Educação Infantil, Ensino Fundamental I e II e Ensino Médio, devendo garantir o 
direito à aprendizagem e o desenvolvimento pleno de todos os alunos. Para tanto a psicopedagogia vem proporcionando ferramentas que auxiliam o processo ensino aprendizagem promovendo a igualdade no sistema educacional, colaborando para a formação integral e para a construção de uma sociedade mais justa, democrática e inclusiva. Assim, acreditamos que a psicopedagogia, seja uma das principais ferramentas que possibilite o desenvolvimento das competências presente na BNCC, pois é de acordo com a reflexão/ação sobre a prática pedagógica dos professores que a mudança acontece contribuindo no processo ensino aprendizagem de modo concreto e eficaz, dando suporte ao professor e ao aluno.

\section{2.-BNCC-Base Nacional Comum Curricular.}

A Base Nacional Comum Curricular (BNCC) é um documento que regulamenta quais são as aprendizagens essenciais a serem trabalhadas nas escolas brasileiras públicas e particulares de Educação Infantil, Ensino Fundamental e Ensino Médio para garantir 0 direito à aprendizagem e 0 desenvolvimento pleno de todos os estudantes. Por isso, é um documento importante para a promoção da igualdade no sistema educacional, colaborando para a formação integral e para a construção de uma sociedade mais justa, democrática e inclusiva. A Base Nacional Comum Curricular (BNCC) é um documento de caráter normativo que define o conjunto orgânico e progressivo de aprendizagens essenciais que todos os alunos devem desenvolver ao longo das etapas e modalidades da Educação Básica. (BRASIL, 2016, p. 7)

O objetivo principal, presente no documento introdutório da BNCC, é oferecer suporte às propostas curriculares, trazendo a preocupação com as especificidades que caracterizam as escolas brasileiras (BRASIL, 2016). O objetivo sinaliza para a necessidade de que a BNCC não ignore a realidade das escolas, os pensamentos e concepções sobre ensino e educação que nelas estão presentes, bem como as questões relacionadas com o ensino e a aprendizagem dos alunos.

Ao ter como objetivo nortear os currículos dos estados e municípios de todo o Brasil a partir dessas perspectivas, a BNCC coloca em curso o que está previsto no artigo nove da Lei de Diretrizes e Bases da Educação (LDB) sancionada em 1996.

Segundo a LDB, cabe ao Governo Federal "estabelecer, em colaboração com os Estados, o Distrito Federal e os Municípios, competências e diretrizes para a educação infantil, o ensino fundamental e o ensino médio, que nortearão os currículos e seus conteúdos mínimos, de modo a assegurar formação básica comum".

É preciso, pensar num Projeto Político-Pedagógico que possa dialogar com a Base Curricular e suas possíveis inovações, garantindo o direito e a valorização da intervenção de todos nessa construção que fundamenta a educação Nacional. 0 documento preliminar da Base Nacional Curricular apresenta conteúdos que foram intensamente discutidos por diversos grupos que interagiram e construíram coletivamente a proposta. Na medida em que esses grupos incorporaram experiências, percepções e projetos de sucesso, os conteúdos e os métodos de ensino e aprendizagem escolhidos certamente serão garantia de maior inclusão e qualidade de ensino. 


\section{3.-Competência.}

Competência é uma qualidade de apreciar e resolver um problema, envolvendo a sua capacidade, habilidade, aptidão e idoneidade. Indivíduos competentes, dentro das mais variadas atividades profissionais, tendem a ser bem-sucedidos.Na sociedade atual, as competências são essenciais para que o indivíduo tenha sucesso em sua vida social e na carreira. A forma de conduzir suas relações, responsabilidades e profissão são determinadas por sua capacidade de a cada dia conviver e resolver as situações cotidianas, cujos resultados são totalmente dependentes da forma com que os seus problemas são solucionados. 0 mercado de trabalho necessita de pessoas capazes de tomar decisões; liderar; resolver conflitos; utilizar conhecimento adquiridos. (DINIZ,2018). Na BNCC, a competência é definida como a mobilização de conhecimentos (conceitos e procedimentos), habilidades (práticas, cognitivas e soco emocionais), atitudes e valores para resolver demandas complexas da vida cotidiana, do pleno exercício da cidadania e do mundo do trabalho.

Ao definir essas competências, a BNCC reconhece que a "educação deve afirmar valores e estimular ações que contribuam para a transformação da sociedade, tornando-a mais humana, socialmente justa e, também, voltada para a preservação da natureza" (BRASIL,2013), ao longo do processo acadêmico.

A BNCC estabelece 10 competências gerais que deverão ser trabalhadas desde a educação infantil até o ensino médio. Dessa forma, o objetivo é que as escolas deixem de ser apenas transmissoras de conteúdo, para auxiliarem o estudante a lidar com as questões emocional, cultural, tecnológica, socioambiental, responsabilidades, criatividade, entre outros.

Tendo então como competências gerais:

1. Conhecimento: - Entender e explicar a realidade, continuar aprendendo e colaborar com a sociedade; analisando as opções para melhores escolhas.

2. Pensamento científico, crítico e criativo:-Exercitar a curiosidade intelectual e recorrer à abordagem das ciências. Inclui-se a investigação, a reflexão, a análise crítica, a imaginação e a criatividade; investigando, elaborando e testando, formulando e resolvendo problemas e criando soluções com base nos conhecimentos das diferentes áreas.

3. Repertório cultural:- Valorizar as diversas manifestações artísticas e culturais, das locais às mundiais; participando de práticas diversificadas da produção artísticocultural.

4. Comunicação:-Utilizar diferentes linguagens, bem como conhecimentos das linguagens artística, matemática e científica; expressando e partilhando informações e experiências em diferentes contextos e produzindo sentidos que levem ao entendimento mútuo.

5. Cultura digital:- Área relativamente nova na educação, visa compreender, utilizar e criar tecnologias digitais de informação e comunicação. Sempre de forma crítica, significativa e reflexiva; Comunicando, acessando e disseminando informações, produzindo conhecimentos, resolvendo problemas e exercendo protagonismo e autoria na vida pessoal e coletiva. 
6. Trabalho e projeto de vida:-Valorizar a diversidade de saberes e vivências culturais e apropriar-se de conhecimentos e experiências; entendendo as relações próprias do mundo e fazendo escolhas alinhadas ao exercício da cidadania e ao seu projeto de vida.

7. Argumentação: - Argumentar com base em fatos, dados e informações confiáveis; formulando, negociando, defendendo ideias e decisões comuns que respeitem e promovam os direitos humanos, a consciência socioambiental.

8. Autoconhecimento e autocuidado:-Conhecer-se, apreciar-se e cuidar de sua saúde física e emocional; compreendendo na diversidade humana e reconhecendo suas emoções e as dos outros, com capacidade para lidar com elas.

9. Empatia e cooperação:-Exercitar a empatia, o diálogo, a resolução de conflitos e a cooperação; promovendo o respeito ao outro e aos direitos humanos, e fazendo-se respeitar.

10. Responsabilidade e cidadania:- Agir pessoal e coletivamente com autonomia, responsabilidade, flexibilidade, resiliência e determinação; tomando decisões com base em princípios éticos, democráticos, sustentáveis, etc.

Essas competências, presente na BNCC possuem áreas que contribuem para o seu aprendizado e aspectos específicos não devendo partir somente das escolas, mas de todos envolvidos no âmbito escolar, como os gestores escolares, professores, alunos, famílias, secretarias de educação e a sociedade em geral, com ferramentas que dê suporte ao trabalho pedagógico. O objetivo é proporcionar uma transformação na educação para que as escolas possam se adequar aos novos desafios e problemas da sociedade atual.

Assim, compreender a noção das competências presente na BNCC não nos tornará excelentes professores, mas, a partir do entendimento, seremos levados a pensar de modo mais eficaz sobre a nossa atuação, tomando consciência de que a prática docente envolve também uma reflexão teórica daquilo que constitui 0 fazer pedagógico. As competências foram definidas a partir dos direitos éticos, estéticos e políticos assegurados pelas Diretrizes Curriculares Nacionais e de conhecimentos, habilidades, atitudes e valores essenciais para a vida no século 21.

Pressupomos que o objetivo da publicação dessas, seja oferecer referências para que, escolas e professores possam inseri-las em currículos, práticas pedagógicas, materiais didáticos e processos de avaliação da aprendizagem. 0 documento é resultado de pesquisas realizadas no Brasil e no exterior. Trata-se de um trabalho que ainda está aberto a contribuições da sociedade para que possa ser aprimorado.

Ao estabelecer marcos e indicar como as competências evoluem ao longo da educação básica, o documento torna mais fácil para o professor entender o que os alunos precisam desenvolver e como promover e acompanhar os resultados dessas aprendizagens. Portanto, as competências são passos muito importantes para a qualidade da educação do Brasil, elas estabelecem elos que proporcionarão uma aprendizagem significativa. 


\section{4.-Psicopedagogia.}

A psicopedagogia tem como foco de estudo a aprendizagem, nasceu da necessidade de compreender melhor o ser humano aprendiz e as respectivas dificuldades e fatores que influenciam ou interferem nesse processo. Assim, segundo Visca (1987) a Psicopedagogia é uma área que estuda o processo de aprendizagem humana.

Ujiie (2016), destaca que: A Psicopedagogia é uma área de estudo que tem como objetivo a aprendizagem humana, que em sua natureza sistemática é ação social, cognitiva e emocional. Por esta via, a Psicopedagogia é uma ciência abrangente com duplo enfoque: clínico e institucional, ou seja, o atendimento individual e/ou coletivo de sujeitos aprendizes. Esse reconhecimento é devido ao seu papel e a sua ação junto aos professores e alunos nos desafios da dificuldade de aprendizagem nas instituições escolares, pois sua atuação e intervenção poderiam auxiliar 0 aluno com dificuldades de aprendizagem, ou com problemas comportamentais a se integrar e melhorar seu rendimento escolar. Diante disso, o psicopedagogo nas escolas se faz fundamental no acompanhamento do aluno nas suas necessidades especiais, considerando os fatores físico, cultural, emocional, psicológico e pedagógico no qual os alunos estão inseridos. Ou seja, é um profissional que pensa e estuda o aluno numa visão holística. A escola hoje é inclusiva e nela seus sujeitos aprendem e interagem em um ambiente multicultural e sociocultural. $E$ muitos dos profissionais que atuam nelas foram capacitados para fazer esta inclusão de forma efetiva. Assim, os desafios do psicopedagogia está em saber a melhor maneira de intervir para que este processo de ensino aprendizagem possa acontecer de forma consistente e significativa dentro do ambiente escolar.

O papel do psicopedagogo no ambiente escolar é bastante específico, nele 0 psicopedagogo é apto à intervenção psicopedagógico visando a solução dos problemas de aprendizagem, a realização de diagnóstico, a utilizar métodos e técnicas para a prevenção, a avaliação e intervenção inerentes a aprendizagem.

A comunidade escolar deve ter conhecimento de suas atribuições, principalmente os pais e professores, pois estes estão intrinsicamente ligados no processo de ensino aprendizagem do aluno. Os espaços de discussão da escola, como reunião do conselho de classe, reunião de pais e do PPP são excelentes oportunidades de discutir o papel e a atuação desse profissional imprescindível na escola.

A Psicopedagogia constitui-se como uma área do conhecimento que constrói saberes privilegiados para atender às demandas da sociedade contemporânea, uma vez que busca resgatar a complexidade do processo ensino-aprendizagem, possibilitando refletir sobre as inter-relações e interdependências entre os diversos fatores envolvidos no aprendizado.

Além disso, o psicopedagogo possui um importante papel para intervenção junto à família dos alunos, visto que o ambiente familiar também influencia no aprendizado.

O psicopedagogo, juntamente com o professor, são os principais responsáveis pelo desenvolvimento no processo ensino e aprendizagem. É na intervenção que o papel de suporte no planejamento da educação possibilitando melhorias, propondo medidas, visando o progresso dos aspectos qualidades do ensino, promovendo projetos de pesquisa de interesse do ensino, que mudanças acontecem. 
O ensino deve sempre ser trabalhado dentro de um contexto e que seja significativo para cada faixa etária. Contudo, o aluno que não for respeitado com sua bagagem de vida sofrerá um bloqueio, muitas vezes irreversível por toda vida. É necessário, portanto, que no ambiente escolar 0 aluno seja valorizado para que alcance resultados favoráveis na sua aprendizagem acadêmica através conteúdos, mas também contribuir para que o aluno saiba lidar com as questões emocional, cultural, tecnológica, socioambiental, responsabilidades, criatividade, entre outras.

A Psicopedagogia Educacional pode assumir tanto um caráter preventivo bem como assistencial. Na função preventiva, segundo Bossa (2000) cabe ao psicopedagogo perceber eventuais perturbações no processo de aprendizagem, participar da dinâmica da comunidade educativa, favorecendo a integração, promovendo orientações metodológicas de acordo com as características e particularidades dos indivíduos do grupo, realizando processos de orientação.

Já no caráter assistencial, o psicopedagogo participa de equipes responsáveis pela elaboração de planos e projetos no contexto teórico/prático das políticas educacionais, fazendo com que professores, diretores e coordenadores possam repensar o papel da escola frente a sua docência e às necessidades individuais de aprendizagem do aluno.

\section{5.-Ensino aprendizagem.}

Segundo Alexandre (2010), a aprendizagem é entendida como um processo de transformação do comportamento adquirido por intermédio das experiências levantadas por fatores relacionados com aspectos neurológicos, ambientais e emocionais, derivados da interação entre estruturas mentais e o meio ambiente em que está inserido, devendo-se levar em consideração as concepções e costumes que cada indivíduo distingue e avalia como adequados.

O objetivo da educação escolar é a aprendizagem do aluno, que acontece através de um ensino voltado para uma interação dinâmica e sucessiva entre aluno e professor, em que o questionamento, a investigação e a análise de evidências levam 0 aluno a realizar descobertas acerca da realidade, construindo seu conhecimento. A aprendizagem que se deseja, deve estar pautada na lógica, para a construção de uma sociedade sadia, uma conscientização democrática com formação para a cidadania.

Segundo LIBÂNEO (1994, p. 90) "a relação entre ensino e aprendizagem não é mecânica, não é uma simples transmissão do professor que ensina para um aluno que aprende." Ele mesmo concluiu que é algo bem diferente disso "é uma relação recíproca na qual se destacam o papel dirigente do professor e a atividade dos alunos." Dessa forma podemos perceber que "O ensino visa estimular, dirigir, incentivar, impulsionar o processo de aprendizagem dos alunos."

Ensinar envolve toda uma estrutura que tem por finalidade alcançar a aprendizagem do aluno através de conteúdo. A relação de ensino e aprendizagem não deve ter como base a memorização, por outro lado os alunos também não devem ser deixados de lado sozinhos.

Díaz (2011), ressalta que não se deve esquecer que a aprendizagem é um processo complexo, pois nele intervêm muitos fatores internos de tipo psicológico e biológico 
que interagem entre si e ambos com o meio externo e que estão presentes em cada pessoa, marcando a individualidade da aprendizagem que se manifesta, por exemplo, quando todos recebem o mesmo ensino, porém cada qual aprende de forma diferente.

Quando se está em sala de aula o professor tem por objetivo que os alunos que estão presentes saiam com o conteúdo assimilado, este, portanto é seu objetivo e para que este objetivo seja alcançado o professor irá se utilizar de um método, que de forma simples é o caminho realizado para se atingir um objetivo, passa pelos métodos que são os meios para realizar objetivos (LIBÂNEO, 1994).

Os métodos que serão empregados vão depender do local, idade, nacionalidade, realidade social e diversos outros fatores que influenciam a forma de aprender do aluno. Assim, para algumas turmas o método expositivo será de maior aceitação e com uma melhor aprendizagem, já em outra turma pode acontecer que seja necessário a elaboração conjunta ou outros métodos. De qualquer maneira a forma que a aula irá ser ministrada depende da turma e da forma que o professor encara seu local de trabalho.

Freire (1996) destaca que, na prática da formação docente, o aprendiz de educador deve perceber como indispensável desenvolver um pensamento reflexivo e crítico propiciado pela mediação do professor e do estudo contínuo. Davis e Oliveira (1993) iniciam seu estudo destacando que é necessário que docentes compreendam as teorias de ensino e aprendizado de forma crítica para que proporcionem e facilitem a apropriação de conhecimentos por parte do aluno. Dessa forma, os professores poderão avaliar criticamente os conteúdos escolares e os métodos de ensino, favorecendo assim a aprendizagem escolar e 0 aluno possa apresentar desenvolvimento efetivo.

O processo de ensino e aprendizagem não é algo simples, ele engloba diversas medidas que devem ser tomadas ou evitadas para que o aprendizado do aluno realmente aconteça, é necessário assim, que o professor realize um planejamento de suas aulas levando em consideração as necessidades dos alunos, a melhor maneira de aplicar um conteúdo, o melhor método e técnica a ser usada em determinados momentos. Perceber o contexto social dos alunos também é importante para que seu conteúdo e exemplos sejam presentes na realidade dos alunos.

Não adianta querer transmitir conteúdos muito complexo para alunos que nem mesmo possuem o domínio da leitura ou não sabem realizar contas simples. Por isso o método é tão importante, o professor através da observação vai ser capaz de descobrir quais os pontos fortes e fracos da turma e qual a melhor maneira deles aprenderem. Cada método possui uma função seja a de estimular o aluno ao debate ou de ajudá-lo a compreender algum conteúdo no âmbito de sua realidade local.

Assim, quanto mais variados forem as ferramentas ou estratégias utilizadas no processo ensino aprendizagem pelo professor, maiores serão as chances dos seus objetivos serem alcançados de modo concreto dentro do ambiente escolar, apesar dos desafios que enfrentam, para tanto como já fora dito os métodos devem ser: dinâmicos, inovadores, variados e que leve o aluno a aprender fazendo, e que esteja de acordo com sua realidade, pois isso proporcionara a quem aprende diferentes formas de ver e refletir sobre sua importância na sociedade, dessa forma, pode-se 
colocar que a aprendizagem humana é determinada pela interação entre o indivíduo e o meio em que participam, os aspectos biológicos, psicológicos e sociais.

\section{6.-Conclusão.}

A Base Nacional Comum Curricular (BNCC) é um documento que regulamenta quais são as aprendizagens essenciais a serem trabalhadas nas escolas brasileiras públicas e particulares de Educação Infantil, Ensino Fundamental e Ensino Médio para garantir 0 direito à aprendizagem e 0 desenvolvimento pleno de todos os estudantes. Por isso, é um documento importante para a promoção da igualdade no sistema educacional, colaborando para a formação integral e para a construção de uma sociedade mais justa, democrática e inclusiva. A BNCC estabelece dez competências gerais que deverão ser trabalhadas desde a educação infantil até 0 ensino médio. Dessa forma, o objetivo é que as escolas deixem de ser apenas transmissoras de conteúdo, mas auxiliem o estudante a lidar com as questões emocional, cultural, tecnológica, socioambiental, responsabilidades, criatividade, entre outros. Nesse sentido, trabalhar essas competências e habilidades de maneira gradual e integrada, alinhadas ao desenvolvimento socio emocional e com objetivos de conhecimento claros para cada ano ou ciclo é muito importante para a formação de um aluno preparado para alcançar o sucesso.

Então a Psicopedagogia/psicopedagogo vem como intermediador entre o professor, aluno e o processo ensino aprendizagem; a fim de manter sempre o propósito de uma aprendizagem que possibilite a interação entre ambos. Ela propõe e auxilia no desenvolvimento de ferramentas favoráveis às mudanças educacionais, visando à descoberta e o desenvolvimento da capacidade do aluno, bem como contribuindo para que os mesmos sejam capazes de olhar o mundo em que vive sabendo interpretá-lo, sem este profissional na escola, muitas crianças poderiam ser estigmatizadas ou deixadas à margem da aprendizagem, o que refletiria no possível insucesso escolar ou social, não tendo condições de prosseguir com segurança e eficiência para uma vida adulta de sucesso. Podemos então perceber o quanto a psicopedagogia/psicopedagogo é importante na instituição escolar, levando-se em conta as competências como inovadoras as quais possam implementar efetivamente mudanças concretas no processo ensino aprendizagem.

\section{7.-References.}

Alexandre, S.F. (2010). Aprendizagem e Suas Implicações no Processo Educativo. Revista de Letras da UEG. São Luís de Montes Belos.

Barbosa, J.J. (2006). Alfabetização e leitura. São Paulo: Cortez, 2006.

Bakhtin, M. (2002). Estética da criação verbal. São Paulo: Martins Fontes.

Diniz, J.J. (2018). Bezerra Fábrica de Vencedores: aprendendo a ser gigante. São Paulo: Novo Século. 
Demo, P. (2000). Pesquisa: Princípios científicos e educativos. São Paulo: Cortez.

Freire, P. (2003). A importância do ato de ler: em três artigos que completam. São Paulo: Cortez.

Libâneo, J.C.O. (1994). Processo de ensino na escola. São Paulo: Cortez.

Martins, G.A., \& Pinto, R.L. (2001). Manual para elaboração de trabalhos acadêmicos. São Paulo: Atlas.

Possebom, A. (2008). Práticas de leitura na educação. Vargem Grande. Disponível em: <http://www.webartigosos.com/articles/9312/1/praticas-de-leitura-na-educacaoinfantil/pagina1.html>

Visca, J. (1997). Clínica Psicopedagogia - epistemologia convergente. Porto Alegre: Artes Médicas. 